\title{
Optimal Central Bank Intervention in the Foreign Exchange Market of Iran
}

\author{
Hajar Jahangard ${ }^{1}$ \\ ${ }^{1}$ Faculty of Economics, University of Tehran, Iran \\ Correspondence: Hajar Jahangard, Economic Research and Policy Department, Central bank of Iran, Tehran, \\ Iran. Tel: 98-21-2995-4401. E-mail: jahangardh@yahoo.com
}

Received: February 11, 2013

Accepted: January 15, 2015

Online Published: March 25, 2015

doi:10.5539/ijef.v7n4p146

URL: http://dx.doi.org/10.5539/ijef.v7n4p146

\begin{abstract}
The article pioneers the designing of a theoretical model for the optimal foreign exchange intervention in Iran. The model used is a nonlinear dynamic programming model with stochastic continuous functions to solve which the Uhlig program has been used. The results indicate that determining the best volume of intervention depends on the economic objectives of policymakers, the exchange rate of the present time, and the future exchange rate expected by the monetary authorities. Due to the monopolistic condition of the government in the foreign exchange market, the volume of the foreign exchange intervention in the market depends on the level the government is trying to keep the exchange rate at the present time as well as the next period. The exchange rate in Iran is not solely determined on the basis of the market mechanisms; therefore, the determinant of the volume of intervention by the monetary authority at the present time is the level that the government attempts to keep the exchange rate at present and in the future. The present and future levels of the exchange rate depend on the government budget expenditures. This in turn depends on the government size and its reliance on foreign exchange revenues received from the sale of oil.
\end{abstract}

Keywords: exchange rate, foreign exchange market of Iran, central bank intervention, Uhlig program, Nonlinear Dynamic Stochastic programming

\section{Introduction}

Foreign exchange market intervention is, most broadly defined, any transaction or announcement by an official agent of a government that is intended to influence the value of an exchange rate or the country's stock of foreign exchange reserves. In most countries, intervention operations are implemented by the monetary authority, although the decision to intervene can often also be made by authorities in the finance ministry or treasury department, depending on the country.

Foreign exchange intervention in Iran is different from intervention in other economies with a market mechanism, as the Iranian economy is strongly oil-reliant. Foreign exchange intervention in Iran is directed by the Central Bank, due to its legal obligation to finance the resources required by the government. In other words, annual budget laws of the government delineate the network for the management of foreign exchange resources upon the determination of the amount of the foreign exchange to be allocated, issuance of the license for the allocation of oil revenue, issuance of the license for the financing of the contracts, and confirmation of receipt and payment channels of foreign exchange by the Central Bank. Based on Section B, note 2, Single Article of the Budget Law for 2014/15, the Ministry of Petroleum is obliged, through competent governmental subsidiaries, to deposit all the revenues received from the exports of crude oil and gas condensates into relevant accounts in the Treasury General, through the Central Bank directly.

According to Paragraph B, Note 2, Single Article of the Budget Law for $1393(2014 / 15)$, the share of the National Iranian Oil Company (NIOC) in the value of oil production (including crude oil and gas condensate) is set at 14.5 percent. Therefore, on the basis of the Budget Bill for 2014/15, the share of the NIOC, including oil and gas buyback contracts, is determined at $\$ 7.5$ billion.

Based on Paragraph H, Article 84 of the 5th Five-Year Development Plan, the share of the National Development Fund of Iran (NDFI) in total exports of crude oil, gas condensate, and natural gas was set to increase by 3 percentage points in each year compared with the year before. Thus, it was determined that the 
mentioned share should rise to 20 percent in 1389 (2010/11) and 1390 (2011/12), 23 percent in 1391 (2012/13), and 26 percent in total exports of crude oil and gas condensate in $1392(2013 / 14)$. On the basis of the 2013/14 Budget Amendment, however, it was envisaged that NDFI's share should decrease to 20 percent. On this basis, it was decided that the resources thereby received (emanating from the difference of 20 and 26 percent) should be left at the government's disposal to be allocated for the financing of relevant projects. According to Paragraph B, Note 2, Single Article of the Budget Law for 2014/15, the amount deposited to the NDFI's account is set at 29 percent of the value of crude oil and gas condensate exports.

In the Budget Law for 2013/14, it was projected that 2 percent of the resources received from the exports of crude oil and gas condensate should be allocated for the payment of Nowrouz bonus to the civil servants, workers, and pensioners in 1391 (2012/13). As this budgetary item was not actualized, the mentioned 2 percent was eliminated from the Budget Amendment of 2013/14. With the inclusion of the mentioned 2 percent in the Budget Law for 1393 (2014/15), NDFI's share increases to 31 percent.

Considering the 29 percent share in the total cash value of the exports of crude oil and gas condensate as well as the 2 percent share for the payment of Nowrouz bonus, the share of NDFI is set at $\$ 14.7$ billion. Therefore, given the share of the NIOC at $\$ 7.5$ billion, share of the NDFI at $\$ 14.7$ billion, and the 2 percent share for Nowrouz bonus, the share of the government general budget (less: repayments for oil and gas buyback contracts) is determined at \$29.4 billion.

In the Budget Law for 1393 (2014/15), revenues from the sale of crude oil (budgetary item 210101) is set at Rls. 752902.6 billion ( $\$ 28411.4$ million), and the equivalent value of the 2 percent share of the deprived and oil-producing regions in the sales of crude oil and gas condensate (budgetary item 210109) is determined at Rls. 25090.5 billion ( $\$ 946.8$ million), totaling Rls. 777993 billion ( $\$ 29358.2$ million).

After realization of the share of government general revenues and upon the sale of the foreign exchange on spot prices, subject of Budgetary Item No. 210101 (as stipulated in Table No. 5) as well as 2 percent of the funds received from crude oil exports, subject of Article 132 of the $5^{\text {th }}$ Five-Year Economic, Social, and Cultural Development Plan, the Central Bank is obliged to deposit the excess foreign exchange received from the sale of oil to the Oil Stabilization Fund (OSF), after financing the uses of the subject of Paragraph 2 of the Budget Law for 2014/15, and implementing its Notes.

As the Central Bank is obliged to finance the Budget (in Rials), excess supply of foreign exchange as compared to market demand is purchased by the Central Bank for the purpose of the management of foreign exchange, as in previous years.

However, according to Paragraph B, Note 2, Single Article of the Budget Law for 1393 (2014/15), the Central Bank is required to deposit the differential of foreign exchange sales (in Rials), based on the benchmark stipulated in the Budgetary Item No. 210101 (sale of crude oil) and the daily exchange rate, to the Treasury General Accounts. Meanwhile, the ceiling for budgetary items (in Rials) to which foreign exchange revenues are deposited is annually set in budget laws. Therefore, setting the foreign exchange rate in the Budget Law and its increase or decrease will not affect the ceilings in Rials (for instance, budget law for 1393 (2014/15) was set at Rls. 26500 per dollar in comparison with Rls. 24500 per dollar in the year before). It is of special note that the Central Bank is implicitly obliged to prevent the fall in the foreign exchange rate in the aftermath of the injection of proceeds received from the sale of oil (in dollars) into the market. In other words, the central bank of Iran is responsible for financing of government's budget. It means that the central bank is not separate from the ministry of finance. That's the reason why, political decisions has already influenced the central bank operations.

When the market faces an excess supply, the Central Bank purchases the government foreign exchange so that it could finance the resources required by the government (in Rials); at the expense of the increase in monetary base and liquidity. The most important factor behind the rise in the monetary base over the recent years is Central Bank's net foreign assets which is in turn due to the rise in Central Bank foreign assets as a result of purchasing foreign exchange from the government for the financing of Budget resources (in Rials), and frequent withdrawals from the OSF and its impartial sale in the market. It is clear that increase in the utilization of the oil revenue in annual budget laws of the government requires more foreign exchange purchases from the government by the Central Bank, for the financing of the Budget (in Rials). The higher the share of government foreign exchange revenues in compensating for the under-realization of Rial revenues, the higher the pressures on the Central Bank to purchase government foreign exchange. The central bank must reduce the danger of large budget if oil prices decline suddenly, and is now being done by, manipulating of foreign exchange market.

Determination of the optimal level of foreign exchange intervention merits a special attention in Iran as government budget is highly reliant on oil. Increase in government reliance on oil revenue makes the 
government vulnerable against oil and the global economy. In this respect, the government should have an optimal presence so that the "non-government" sector could have a positive contribution to the economy. Therefore, the most significant objectives of foreign exchange intervention could be outlined as: (1) optimization of the presence of the "government" in the economy, and (2) facilitation of the presence of the "non-government" sector in the foreign exchange market. Foreign exchange intervention policy will be effective only if the market logic accepts it. Furthermore, Central Bank intervention as a policy instrument will play a pivotal role when the market logic is congruent. In other words, foreign exchange intervention is not independent of other economic policies and therefore its effectiveness depends on the optimal utilization of economic, monetary and fiscal policies. This article casts a special look on the government intervention in the market and aims at designing an appropriate model for the determination of the optimal level of foreign exchange intervention in Iran.

\section{Literature Review}

A few research studies have been conducted on the estimation of the optimal level of intervention in the foreign exchange market. Most studies of this nature aim at designing a one-dimensional model for stochastic impulse control. Mundaca and Oksendal (1998) came up with the optimal control model of the exchange rate under uncertainty. On the other hand, Cadenillas and Zapatero (1999) designed the optimal foreign exchange control model based on the supposition of exchange rate target zones. On this basis, the foreign exchange rate is supposed to be kept close to its mean value. In another study, Cadenillas and Zapatero (2000) formulated an optimal stochastic control problem by which intervention and interest rate are used as two policy instruments to achieve the foreign exchange objective. The goal of Onishi and Tsujimura (2006) was to find an optimal control of minimization of the total expected costs in an infinite time horizon. Overall, such studies are solely focusing on designing a stochastic control model. The article, however, utilizes a nonlinear dynamic programming model with continuous stochastic functions, which is solved by Uhlig Program. The model used is based on Cadenillas and Zapatero model (2000), with a dynamic and multidimensional design specific to the economy of Iran, which is extended and solved based on Uhlig program. The paper shows that huge injection of oil revenues directly to economy and also the absence of potent structure of output are inclusively caused the central bank intervention in the form of foreign exchange buying in the market. This direct to high inflation and low output. After that, the optimal foreign exchange intervention model based on analysis has been designed mathematically. The structure of the paper is as follows: in section 2, the exchange rate, inflation rate, output dynamics, and the Central Bank objective are designed; in section 3, the value function has been characterized; and in section 4, the Uhlig Program is utilized to solve the model. Later, the optimal control law of variables and elasticities are extracted and interpreted. Finally, the conclusion is given.

\section{Model}

The model designed for this article, tailored to the requirements of Iran for the first time, is a nonlinear dynamic programming model with stochastic and continuous functions. It is hypothesized that state variables in this article namely, foreign exchange rate, output, and inflation rate follow the Brownian motion (Karatzas \& Shreve, 1991). The control variable is the amount of foreign exchange intervention in the market which follows an autoregressive process. What follows is the formulation of the laws of motion of the state and control variables in the nonlinear dynamic programming model of intervention in the foreign exchange market in Iran.

\subsection{Foreign Exchange Rate Dynamics}

In the economy of Iran, Central Bank liabilities to the financing of government foreign exchange resources, in national currency, has led to Central Bank intervention in the market through the purchasing of the excess supply of foreign exchange. Financing of a remarkable share of Budget uses in Iran is implemented out of the revenues received from oil exports, as well as the balance of the OSF. Therefore, Central Bank commitment to financing the Rial resources of the budget gives the Central Bank no choice but to purchase foreign exchange in the market at a predetermined rate in order to settle the market. Therefore, determination of the foreign exchange rate in the economy of Iran is fulfilled with due consideration of financing government budget resources. In fact, government intervention in the market is aimed, by purchasing the excess foreign exchange, to stabilize the foreign exchange rate. We assume that foreign exchange rate $(x)$ is an adapted stochastic process given by:

$$
x_{t+1}=x_{0}+\int_{0}^{t} \mu_{s} d s+\int_{0}^{t} \sigma_{s} d W_{s}+\sum_{0}^{t-1} I\left(\zeta_{s}\right)
$$

Based on the equation, $(x)$ is just a geometric Brownian motion which is affected by the exogenous economic pressure $(\mu)$, like the financing of government general budget (in Rials) $\left(\mu_{\mathrm{s}} \in \mathrm{R}\right)$. Therefore, $\mu_{\mathrm{s}}>0$ will indicate 
devaluatory pressures as a result of political reasons for instance, and $\mu_{\mathrm{s}}<0$ will indicate the opposite. Parameter $\sigma_{\mathrm{s}}>0$ is the exogenous fluctuation of the foreign exchange variable due to other political and economic variables (such as oil price fluctuations and international sanctions). According to economic literature, parameter $\mu_{\mathrm{s}}$ is called drift and parameter $\sigma_{\mathrm{s}}$ is known as volatility. $x_{0}$ is the foreign exchange rate at the starting time, $w_{\mathrm{s}}$ is the foreign exchange shock with the Wiener process and the function $I\left(\zeta_{s}\right)$ is the impact of foreign exchange intervention on the foreign exchange rate. $\mu_{\mathrm{s}}, \sigma_{\mathrm{s}}$ are Brownian stochastic motion parameters which depend on the volume of foreign exchange rate and time. Therefore, foreign exchange rate is affected by the pressures emanating from financing of government budget (in Rials) and the amount of Central Bank intervention in the foreign exchange market $\left(\zeta_{s}\right)$. The larger the amount of government budget and its reliance on oil revenue, the higher the pressure on the Central Bank for the Rial financing of the Budget.

The exchange rate at time $t+1$ is a function of the starting exchange rate, total exogenous economic pressures until $t$, total exogenous foreign exchange rate fluctuations until $t$, and the impact of the intervention on the exchange rate. The impact of foreign exchange intervention explained below is assumed as a discontinuous process. This is due to the fact that intervention takes place when the exchange rate deviates from the exchange rate target. Based on the Riemann-Stieltjes integration (L.C Evans, 2010), the exchange rate function $x_{t}$ could be explained as in the following discontinuous function:

$$
x_{t+1}=x_{t}+\mu_{t}^{x} x_{t-1}+\sigma_{t}^{x} x_{t-1} d w_{t}+I\left(\zeta_{t-1}\right)
$$

Where $d w_{t}=\varepsilon_{t} \sqrt{d t}$ and $\varepsilon_{t}$ is the foreign exchange shock which is identically and independently distributed (i.i.d). $x_{t+1}$ is the exchange rate at time $t+1, x_{t}$ is the exchange rate at time $t, x_{t-1}$ is the exchange rate at time $t-1$, the function $I\left(\zeta_{t-1}\right)$ is the impact of the foreign exchange intervention of the previous period on the exchange rate, $\mu_{t}^{x}$ is drift (mean) and $\sigma_{t}^{x}$ is the exchange rate fluctuation at time $t$ (variance).

\subsection{Inflation Rate Dynamics}

$$
\pi_{t+1}=\pi_{0}+\int_{0}^{t} \mu_{s} d s+\int_{0}^{t} \sigma_{s} d w_{s}+q \int_{0}^{t}\left(x_{s}-\bar{x}\right) d s+f \int_{0}^{t}\left(y_{s}-\bar{y}\right) d s
$$

As seen in the above equation, the inflation rate follows the geometric Brownian motion. $\pi_{0}$ is the inflation rate at time $0, \mu_{s}$ is the exogenous economic pressure on the inflation rate, $\sigma_{\mathrm{s}}$ is the exogenous fluctuation in inflation due to other economic and political variables, $w_{s}$ is the inflation shock with the Wiener process. Constant coefficients $q$ and $f$ illustrate the impact of the foreign exchange rate fluctuations and output gap on the inflation rate, respectively. $x_{t}$ is the exchange rate at time $t, \bar{x}$ is the exchange rate target, $y_{t}$ is the value of output at time $t$, and $\bar{y}$ is the equilibrium output or target. $\mu_{s}, \sigma_{s}$ are the Brownian motion parameters which depend on the inflation rate and time.

Many economists design three-gap models for the developing economies so that they could emphasize the impact of foreign exchange variations, which play a significant role in the economy, on the strengthening of inflationary dynamics (Taylor, 1991). Inflation is by nature a two-dimensional dynamic flow. Although inflation has an inevitable monetary dimension, prices are determined by government expenses. Therefore, in order to explain inflation, expenses and their determining factors should be taken into consideration in addition to liquidity and monetary variables.

Exchange rate changes influence the general level of prices through total supply and demand. On the supply side, the exchange rate directly affects import prices. The intensity and timing of the impact on domestic prices is not certain as they depend on the nature of long-run contracts, non-price responses of foreign firms to exchange rate changes, and the share of imports in total economy. Meanwhile, exchange rate fluctuations could have an indirect supply effect on domestic prices. The contingent rise in the expenses of imported inputs (in dollars) due to the currency depreciation will raise the marginal cost which will in turn lead to an increase in the price of domestically-manufactured commodities. Firms will raise prices in order to improve their profit margins. The amount of price rise depends on the market structure, number of domestic and foreign firms in the market, and the degree of substitutability between goods.

Exchange rate also affects inflation through the aggregate demand. For example, a depreciation of the domestic currency can lead to a rise in inflation because of the pass-through from higher import prices and greater demand for the country's exports. With the rise in the aggregate demand, the level of prices increases which leads to a 
rise in output. With the growth in the output, demand for inputs and labor force will rise, which has an ensuing effect on the increase of the price of inputs and wages. Increase in wages is devoted to the price rise fueled by economic firms. Price rises resulting from currency depreciation are added to price-wage dynamics (Kan, 1987; Huffer, 1989; Deravi \& Gregorowicz et al., 1995).

As this paper tries to design a theoretical model for the optimal foreign exchange intervention in the market of Iran, not all determinants of the inflation model are considered in detail. In other words, all factors affecting inflation namely, money, liquidity, wages, etc., are included in $\sigma_{\mathrm{s}}$ and $\mu_{\mathrm{s}}$ fluctuation parameters. On this basis, inflation is influenced by exogenous economic pressures, foreign exchange rate, output gap, and inflationary shocks.

Based on the Riemann-Stieltjes integration, inflation rate discontinuous function is as follows:

$$
\pi_{t+1}=\pi_{t}+\mu_{t}^{\pi} \pi_{t-1}+\sigma_{t}^{\pi} \pi_{t-1} d w_{t}+q x_{t-1}\left(x_{t}-\bar{x}\right)+f_{y_{t-1}}\left(y_{t}-\bar{y}\right)
$$

where $d w_{t}=u_{t} \sqrt{d t}$ and $u_{t}$ is the inflation shock (i.i.d).

\subsection{Output Dynamics}

$$
y_{t+1}=y_{0}+\int_{0}^{t} \mu_{s} d s+\int_{0}^{t} \sigma_{s} d w_{s}+h \int_{0}^{t}\left(\pi_{s}-\bar{\pi}\right) d s
$$

Assume that output follows the Brownian stochastic motion where $y_{0}$ denotes the output of the economy at time $0, \mu_{s}$ is the exogenous economic pressure on the output, $\sigma_{s}$ is the exogenous output fluctuation due to other economic and political variables and $w_{s}$ is the output shock. $\mu_{s}, \sigma_{s}$ are the Brownian stochastic motion parameters, depending on the output level and time. Constant coefficient $h$ demonstrates the effect of inflation on output. $\pi_{s}$ is the inflation rate at time $s$ and $\bar{\pi}$ is the aimed inflation rate. Deviation of inflation target affects output. Due to scarcity of inputs, inflation affects output through the marginal cost. In fact, marginal cost is an increasing function of output (Jagjit \& Nolan, 2004). Based on this relation, output is affected by exogenous economic pressures, inflation, and output shocks.

As before, based on Riemann-Stieltjes integration, output discontinuous function is as follows:

$$
y_{t+1}=y_{t}+\mu_{t}^{y} y_{t-1}+\sigma_{t}^{y} y_{t-1} d w_{t}+h \pi_{t-1}\left(\pi_{t}-\bar{\pi}\right)
$$

where $d w_{t}=v_{t} \sqrt{d t}$, and $v_{t}$ is the output shock which is identically and independently distributed (i.i.d).

Now, discontinuous forms of the exchange rate, inflation and output equations, known as "Restriction Equations", are considered as stochastic equations as follows:

$$
\begin{gathered}
x_{t+1}=x_{t}+x_{t-1} \mu_{t}^{x}+x_{t-1} \sigma_{t}^{x}+I\left(\zeta_{t-1}\right)+\varepsilon_{t} \\
\pi_{t+1}=\pi_{t}+\pi_{t-1} \mu_{t}^{\pi}+\pi_{t-1} \sigma_{t}^{\pi}+q x_{t-1}\left(x_{t}-\bar{x}\right)+f y_{t-1}\left(y_{t}-\bar{y}\right)+u_{t} \\
y_{t+1}=y_{t}+y_{t-1} \mu_{t}^{y}+y_{t-1} \sigma_{t}^{y}+h \pi_{t-1}\left(\pi_{t}-\bar{\pi}\right)+V_{t}
\end{gathered}
$$

Here, $\varepsilon_{t}, u_{t}$, and $v_{t}$ are the stochastic shocks of the exchange rate, inflation, and output, respectively (i.i.d). Before we continue, we have to make an assumption about the exchange rate intervention, $\zeta_{\tau}$ at time $\tau$. In case of zero intervention in the foreign exchange market, the exchange rate will only be affected by exogenous economic pressures (pressure of financing of government general budget in Rials) and the exogenous fluctuations of the exchange rate due to other economic and political variables. It has been hypothesized that inflation fluctuations affect output, on the one hand, and the output gap and the exchange rate will affect inflation, on the other hand. It is also hypothesized that $\zeta_{\tau}$ follows an AR process as follows:

$$
\zeta_{t}=\theta \zeta_{t-1}+W_{t}
$$

Where, $|\theta|\left\langle 1\right.$, and $w_{t}$ is an (i.i.d) process. Meanwhile, it is assumed that $I\left(\zeta_{t}\right)=\lambda \zeta_{t}$, where, $\lambda \leq 1$ and the coefficient $\lambda$ illustrates the effect of foreign exchange intervention on the exchange rate. At this point, dynamic processes of state and control variables are designed. At this point, the Central Bank objective function must be designed. 


\subsection{Central Bank Objective Function}

Central Bank, as the monetary authority, should aim at minimizing its loss function. Based on the following relation, the loss function of the central bank is a function of the exchange rate fluctuations (first term), inflation rate fluctuations (second term), output gap (Taylor Rule) (third term), and organizational costs of foreign exchange interventions (fourth term):

$$
\text { Min } J=E\left\{\int_{0}^{\infty} e^{-\lambda t}\left[\alpha_{\delta}\left(x_{t}-\rho\right)^{2 \delta}+k\left\{(1-\imath)\left(\pi_{t}-\bar{\pi}\right)^{2}+\imath\left(y_{t}-\bar{y}\right)^{2}\right\}\right] d t+\sum_{i=1}^{\tau(\infty \infty} e^{-\lambda \tau_{i}} g\left(\zeta_{i}\right)\right\}
$$

Here, $J$ is the loss function of the central bank, $E$ is the expected value (mathematical expectation), $\alpha_{\delta}$ is the relative weight given by the Central Bank to foreign exchange fluctuations from the targeted or equilibrium exchange rate. $x_{t}$ is the exchange rate at time $t, \rho$ is the exchange rate targeted by the Central Bank, $\delta= \pm 1$ is an index to show the different effects of exchange rate fluctuations above and below the exchange rate target, $k$ is the effect parameter of output gap and inflation on the loss of the Central Bank, $l$ is the relative weight given by the Central Bank to output fluctuations against the inflation fluctuations, $1-t$ is the relative weight given by the Central Bank to inflation fluctuations against the output fluctuations, $\bar{\pi}$ is the inflation target, $\bar{y}$ is the output target, $\zeta$ is the intensity of foreign exchange intervention in the foreign exchange market, $\tau$ is the time of the foreign exchange intervention in the market, $g(\zeta)$ is the cost function of Central Bank intervention. As is seen in the equations of exchange rate, inflation, and output, $x_{t+1}$ is a function of $\zeta_{t}$. However, $\pi_{t+1}, y_{t+1}$ do not have such a characteristic.

$g\left(\zeta_{t}\right)$ is a cost function. If we hypothesize that the Central Bank is aiming at minimizing its intervention in the foreign exchange market, the optimal change in the exchange rate resulted from the Central Bank intervention will be equal to zero. Therefore, function $g$ can be defined as follows:

$$
g\left(\zeta_{t}\right)=\psi\left(\zeta_{t}-0\right)^{2}=\psi \zeta_{t}^{2}
$$

Meanwhile, Central Bank's loss function can be rewritten as follows:

$$
\begin{gathered}
\text { Min } J=E\left\{\int_{0}^{\infty} e^{-\lambda t}\left[\alpha_{\delta}\left(x_{t}-\rho\right)^{2 \delta}+k\left\{(1-\imath)\left(\pi_{t}-\bar{\pi}\right)^{2}+\imath\left(y_{t}-\bar{y}\right)^{2}\right\}\right] d t+\psi \sum_{\tau=1}^{\tau<\infty} e^{-\lambda \tau} \zeta_{\tau}^{2}\right\} \\
\tau=1,2, \ldots, t-1
\end{gathered}
$$

Since the objective is minimizing the expected loss function of the Central Bank, mathematically, some hypotheses must be made on the bounded functions (Note 1). In fact, in order to find acceptable responses, bounded loss function of the Central Bank must be hypothesized. The hypothesis for the bounded measurable functions of exchange rate fluctuations, inflation, and output leads to the following relations:

$$
\begin{gathered}
E\left\{\int_{0}^{\infty} e^{-\lambda t} \alpha_{\delta}\left(x_{t}-\rho\right)^{2 \delta} d t\right\}<\infty \\
E\left\{\int_{0}^{\infty} e^{-\lambda t} k\left\{(1-\imath)\left(\pi_{t}-\bar{\pi}\right)^{2}+\boldsymbol{\imath}\left(y_{t}-\bar{y}\right)^{2}\right\} d t\right\}<\infty
\end{gathered}
$$

Bounded expectation of intervention costs shows the following:

$$
E\left\{\psi \sum_{\tau=1}^{\tau<\infty} e^{-\lambda \tau} \zeta_{\tau}^{2}\right\}<\infty
$$

The above inequality states: $P\left\{\operatorname{Lim}_{n \rightarrow \infty} \tau_{n} \leq T\right\}=0 \quad \forall T \in[0, \infty)$. The three inequalities above show: (Cadenillas \& Zapatero, 2000).

$$
\operatorname{Lim} \underset{T \rightarrow \infty}{E}\left[e^{-\lambda T} X(T+)\right]=0
$$

Therefore, in this problem, we are looking for an admissible impulse stochastic control (foreign exchange intervention) to set the necessary conditions. By and large, finite solutions are considered.

Generally, integrals in the Central Bank's loss function are stochastic integrals. Solving this type of integrals is 
different from solving ordinary integrals by using conventional methods. For stochastic integrals, there is no exact numerical solution. In this paper, the problem is solved using nonlinear dynamic stochastic models (Uhlig, 1999).

\section{Method}

We need to take the following steps to solve the dynamic stochastic systems with the method of Uhlig. First of all, central Bank's loss function can be written in the discontinuous form as follows (whether continuous or discontinuous, this function does not change the result):

$$
\operatorname{Min} J=E \sum_{t=0}^{\infty} \beta^{t}\left[\alpha_{\delta}\left(x_{t}-\rho\right)^{2 \delta}+k\left\{(1-\imath)\left(\pi_{t}-\bar{\pi}\right)^{2}+\boldsymbol{\imath}\left(y_{t}-\bar{y}\right)^{2}\right\}+\psi \zeta_{t-1}^{2}\right]
$$

Foreign exchange rate $\left(x_{t}\right)$, inflation $\left(\pi_{t}\right)$ and output $\left(y_{t}\right)$ are state variables and foreign exchange intervention $\left(\zeta_{t-1}\right)$ is the control variable. Supposing that this is a recursive problem, Bellman equation can be written as follows (Gong \& Smeller, 2004; Ljungqvist \& Sargent, 2000):

$$
V\left(x_{t}, \pi_{t}, y_{t}\right)=\operatorname{Min}_{\zeta_{t-1}}\left\{\alpha_{\delta}\left(x_{t}-\rho\right)^{2 \delta}+k\left\{(1-\imath)\left(\pi_{t}-\bar{\pi}\right)^{2}+\imath\left(y_{t}-\bar{y}\right)^{2}\right\}+\psi \zeta_{t-1}^{2}+\beta E h\left(x_{t+1}, \pi_{t+1}, y_{t+1}\right)\right\}
$$

Here, $V$ function which solves Bellman equation is called the value function. The value function explains the optimal value of the problem in the form of a function of the state variable $x$.

Foreign exchange $\left(x_{t+1}\right)$, inflation $\left(\pi_{t+1}\right)$ and output dynamics $\left(y_{t+1}\right)$ were previously introduced. Now it is time to take the derivative of Bellman equation (8) with respect to the control variable $\zeta_{t-1}$. Based on the exchange rate equation, $x_{t+1}$ is a function of $\zeta_{t}$; however, $y_{t+1}$ and $\pi_{t+1}$ do not enjoy this feature. If we take the derivative of Bellman equation (8) with respect to the control variable $\zeta_{t-1}$, the usual first order condition (FOC) is resulted:

$$
\frac{\partial V}{\partial \zeta_{t-1}}=2 \psi \zeta_{t-1}+\beta E\left[\frac{\partial V}{\partial x_{t+1}} \times \frac{\partial x_{t+1}}{\partial \zeta_{t-1}}+\frac{\partial V}{\partial \pi_{t+1}} \times \frac{\partial \pi_{t+1}}{\partial \zeta_{t-1}}+\frac{\partial V}{\partial y_{t+1}} \times \frac{\partial y_{t+1}}{\partial \zeta_{t-1}}\right]=0
$$

Considering equations (4), (5), and (6), and $I\left(\zeta_{t-1}\right)=\gamma \zeta_{t-1}$, it can be said:

$$
2 \psi \zeta_{t-1}+\beta \gamma E \frac{\partial V}{\partial x_{t+1}}=0
$$

Taking the derivative of Bellman equation (8) with respect to the state variable $x_{t}$, we get to the famous B-S equation (Benveniste-Schenkman, 1979), or envelope theorem:

$$
\frac{\partial V}{\partial x_{t}}=2 \delta \alpha_{\delta}\left(x_{t}-\rho\right)^{2 \delta-1}
$$

Lead this equation to $\mathrm{t}+1$ and substitute in (9):

$$
2 \psi \zeta_{t-1}+2 \delta \alpha_{\delta} \beta \gamma E\left(x_{t+1}-\rho\right)^{2 \delta-1}=0
$$

Equation (10) is known as Euler Equation. This equation along with (4), (5) and (6), known as restriction equations, are the necessary conditions for solving the problem of minimizing the Central Bank's expected loss function. Therefore, first of all, these equations need to be linearized and then the Uhlig program must be applied to solve them.

To this end, we use the log-linear approximation, which is based on Taylor approximation around the steady state, to replace the equations by approximations which are linear functions in the log-deviations of the variables as follows (Campbell \& Cochrane, 1998).

A. Log-Linearizing the Euler Equation (10): In this equation, only the second term is nonlinear which is approximated as follows: 


$$
\left(x_{t+1}-\rho\right)^{2 \delta-1} \approx(\bar{X}-\rho)^{2 \delta-1}\left\{1+(2 \delta-1)(\bar{X}-\rho)^{2 \delta-2} \frac{\bar{x}}{(\bar{X}-\rho)^{2 \delta-1}} x_{t+1}\right\}
$$

It can still be written in a simpler way:

$$
\left(x_{t+1}-\rho\right)^{2 \delta-1} \approx(\bar{x}-\rho)^{2 \delta-1}+(2 \delta-1)(\bar{X}-\rho)^{2 \delta-2} \bar{X} \quad X_{t+1}
$$

Now, we put the estimation in Euler equation (10):

$$
2 \psi \zeta_{t-1}+2 \delta \alpha_{\delta} \beta \gamma(\bar{x}-\rho)^{2 \delta-1}+2 \delta \alpha_{\delta} \beta \gamma(2 \delta-1)(\bar{x}-\rho)^{2 \delta-2} \bar{X} E\left(x_{t+1}\right)=0
$$

Therefore, relation (11) the log-linearizing the Euler equation is the problem of minimizing the monetary authority's expected loss function.

B. Log-Linearizing the Restriction Equations: Considering (4);

$$
x_{t+1}=x_{t}+x_{t-1} \mu_{t}^{x}+x_{t-1} \sigma_{t}^{x}+\gamma\left(\zeta_{t-1}\right)+\varepsilon_{t}
$$

All the terms are linear. Exchange rate equation can also be considered as this:

$$
x_{t+1}=x_{t}+\left(\mu_{t}^{X}+\sigma_{t}^{X}\right) x_{t-1}+\gamma\left(\zeta_{t-1}\right)+\varepsilon_{t}
$$

Now, we consider the inflation equation (5):

$$
\pi_{t+1}=\pi_{t}+\pi_{t-1} \mu_{t}^{\pi}+\pi_{t-1} \sigma_{t}^{\pi}+q x_{t-1}\left(x_{t}-\bar{x}\right)+f y_{t-1}\left(y_{t}-\bar{y}\right)+u_{t}
$$

The fourth term to the right of the inflation equation (5) using the Taylor approximation is:

$$
\begin{aligned}
x_{t-1}\left(x_{t}-\bar{X}\right) \approx \bar{X} e^{x_{t-1}} & \left(\bar{X} e^{x_{t}}-\bar{X}\right) \\
& \approx \bar{X}^{2} e^{x_{t-1}}\left(e^{x_{t}}-1\right) \\
& \approx \bar{X}^{2}\left(e^{x_{t-1}} e^{x_{t}}-e^{x_{t-1}}\right) \\
& \approx \bar{X}^{2}\left(1+x_{t-1}+x_{t}-1-x_{t-1}\right)=\bar{x}^{2} x_{t}
\end{aligned}
$$

The fifth term to the right of the inflation equation using the Taylor approximation is:

$$
y_{t-1}\left(y_{t}-\bar{y}\right) \approx \bar{y}^{2} y_{t}
$$

Therefore, the log-linearizing the inflation equation is:

$$
\pi_{t+1}=\pi_{t}+\left(\mu_{t}^{\pi}+\sigma_{t}^{\pi}\right) \pi_{t-1}+q \bar{x}^{2} x_{t}+f \bar{y}^{2} y_{t}+u_{t}
$$

Now, we consider the output equation (6):

$$
y_{t+1}=y_{t}+y_{t-1} \mu_{t}^{y}+y_{t-1} \sigma_{t}^{y}+h \pi_{t-1}\left(\pi_{t}-\bar{\pi}\right)+v_{t}
$$

The fourth term to the right of the output equation above (6), using the Taylor approximation is:

Therefore, the log-linearization of the output equation is:

$$
\pi_{t-1}\left(\pi_{t}-\bar{\pi}\right) \approx \bar{\pi}^{2} \pi_{t}
$$

$$
y_{t+1}=y_{t}+\left(\mu_{t}^{y}+\sigma_{t}^{y}\right) y_{t-1}+h \bar{\pi}^{2} \pi_{t}+v_{t}
$$

\section{Discussion of Results}

In this round, the Nonlinear Dynamic Stochastic Model of Foreign Exchange Intervention in Iran will be solved for equilibrium laws of motion. Linear equations (11), (12), (13) and (14) are as follows:

More simply;

$$
\begin{gathered}
2 \psi \zeta_{t-1}+2 \delta \alpha_{\delta} \beta \gamma(\bar{x}-\rho)^{2 \delta-1}+2 \delta \alpha_{\delta} \beta \gamma(2 \delta-1)(\bar{x}-\rho)^{2 \delta-2} \bar{x} E\left(x_{t+1}\right)=0 \\
x_{t+1}=x_{t}+\left(\mu_{t}^{x}+\sigma_{t}^{x}\right) x_{t-1}+\gamma\left(\zeta_{t-1}\right)+\varepsilon_{t} \\
\pi_{t+1}=\pi_{t}+\left(\mu_{t}^{\pi}+\sigma_{t}^{\pi}\right) \pi_{t-1}+q \bar{x}^{2} x_{t}+f \bar{y}^{2} y_{t}+u_{t} \\
y_{t+1}=y_{t}+\left(\mu_{t}^{y}+\sigma_{t}^{y}\right) y_{t-1}+h \bar{\pi}^{2} \pi_{t}+v_{t}
\end{gathered}
$$

$$
\begin{gathered}
a_{1} \zeta_{t-1}+c_{1}+a_{2} E\left(x_{t+1}\right)=0 \\
x_{t+1}=x_{t}+a_{3} x_{t-1}+\gamma \zeta_{t-1}+\varepsilon_{t}
\end{gathered}
$$


So that,

$$
\begin{gathered}
\pi_{t+1}=\pi_{t}+a_{4} \pi_{t-1}+a_{5} x_{t}+a_{6} y_{t}+u_{t} \\
y_{t+1}=y_{t}+a_{7} y_{t-1}+a_{8} \pi_{t}+v_{t}
\end{gathered}
$$

$$
\begin{aligned}
& 2 \psi=a_{1} \\
& 2 \delta \alpha_{\delta} \beta \gamma(\bar{x}-\rho)^{2 \delta-1}=c_{1} \\
& 2 \delta \alpha_{\delta} \beta \gamma(2 \delta-1)(\bar{x}-\rho)^{2 \delta-2} \bar{x}=a_{2} \\
& \left(\mu_{t}^{x}+\sigma_{t}^{x}\right)=a_{3}
\end{aligned}
$$

$$
\begin{aligned}
& \left(\mu_{t}^{\pi}+\sigma_{t}^{\pi}\right)=a_{4} \\
& q \bar{x}^{2}=a_{5} \\
& f \bar{y}^{2}=a_{6} \\
& \left(\mu_{t}^{y}+\sigma_{t}^{y}\right)=a_{7} \\
& h \bar{\pi}^{2}=a_{8}
\end{aligned}
$$

To get to the recursive equilibrium law of motion, we calculate $x_{t}$ from equation (16) and then put the result in Euler equation (15):

$$
x_{t}=-\left\{a_{3} x_{t-1}+\left(\gamma+\frac{a_{1}}{a_{2}}\right) \zeta_{t-1}+\frac{c_{1}}{a_{2}}+\varepsilon_{t}\right\}
$$

As mentioned earlier, the basis of log-linearization is using the Taylor approximation around the steady state. Since variables are taken as log-deviations, coefficients and elasticities are the same. We take as given the exchange rate state variable in the previous period $\left(x_{t-1}\right)$, foreign exchange intervention control variable in the previous period $\left(\zeta_{t-1}\right)$, and realized exchange rate shock at the present time $\left(\varepsilon_{t}\right)$. Using the recursive equilibrium law of motion of exchange rate (19), elasticities substitution can be calculated. Current exchange rate elasticity with respect to the past one is:

$$
\frac{\partial x_{t}}{\partial x_{t-1}}=-a_{3}=-\left(\mu_{t}^{X}+\sigma_{t}^{X}\right)
$$

Here, $\left(\frac{\partial x_{t}}{\partial x_{t-1}}\right)$ is a function of exogenous economic pressures (such as the pressure of financing the government general budget), $\left(\mu_{t}^{x}\right)$, and the exogenous fluctuation of the exchange rate due to other economic variables $\left(\sigma_{t}^{x}\right)$, such as the oil price fluctuations in the international markets. Exogenous economic pressures are upward and downward pressures on the exchange rate. The mentioned elasticity could either be positive or negative, depending on the exogenous economic pressures on the exchange rate and the exchange rate fluctuations. If the elasticity is positive, the economy faces an appreciation of the country's exchange rate which spills over to the exchange rate of the following period. On the other hand, if the elasticity is negative, the economy encounters currency depreciation. In other words, the elasticity between the exchange rates of two consecutive periods, ceteris paribus, depends on the revaluatory or devaluatory pressures of the exchange rate and the exogenous fluctuations of the exchange rate.

Based on the recursive equilibrium law of motion of the exchange rate (19), exchange rate elasticity substitution with respect to foreign exchange intervention is:

$$
\frac{\partial x_{t}}{\partial \zeta_{t-1}}=-\left(\gamma+\frac{a_{1}}{a_{2}}\right)=-\gamma-\frac{2 \psi}{2 \delta \alpha_{\delta} \beta \gamma(2 \delta-1)(\bar{x}-\rho)^{2 \delta-2} \bar{x}}
$$

Exchange rate elasticity substitution with respect to foreign exchange intervention of the previous period depends on various parameters; inter alia, the effect of foreign exchange intervention on the exchange rate $(\gamma)$, the relative weight given by the Central Bank to exchange rate fluctuations from the target $\left(\alpha_{\delta}\right)$, exchange rate target of the Central Bank $(\rho)$, different effects of upward and downward foreign exchange rate deviations from the target $(\delta= \pm 1)$, the cost factor of exchange rate intervention $(\psi)$, the stochastic discount factor of Central Bank costs $(\beta)$, and exchange rate in the steady state of the economy $(\bar{x})$. If Central Bank costs (exchange rate, inflation rate, output fluctuations, and the costs of foreign exchange intervention) are discounted with a higher factor, exchange rate elasticity with respect to the exchange rate intervention of the previous period is lower. If the effectiveness of foreign exchange market intervention is larger, this elasticity is larger too. If the 
cost factor of foreign exchange intervention is larger, the elasticity is larger as well. Based on (19), supposing that no shock happens to the economy $\left(\varepsilon_{t}=0\right)$, and the Central Bank is aiming at determining the exchange rate at this moment and without any presupposition, the exchange rate at time zero, i.e., the exchange rate excluding the shocks and the effect of state and control variables of the previous period, will be:

$$
x_{t=0}=-\frac{c_{1}}{a_{2}}=-\frac{2 \delta \alpha_{\delta} \beta \gamma(\bar{x}-\rho)^{2 \delta-1}}{2 \delta \alpha_{\delta} \beta \gamma(2 \delta-1)(\bar{x}-\rho)^{2 \delta-2} \bar{X}}=\frac{-(\bar{x}-\rho)}{(2 \delta-1) \bar{X}}
$$

The exchange rate at time zero depends on the equilibrium exchange rate or the steady state $(\bar{x})$, exchange rate target of Central Bank $(\rho)$, and the different effects of upward and downward foreign exchange rate fluctuations from the target $(\delta= \pm 1)$.

To come up with a numerical solution to this problem, what we need is the exact information about the value of the parameters such as $a_{i=1}^{8}$. Since the value of these parameters in the Iranian economy is unknown and just few parameters are found in other research documents, calibration cannot be applied. Furthermore, utilization of parameters estimated from similar models is not suitable to the economy of Iran, as these parameters need to be estimated from the beginning, with due consideration of the oil-reliant economy of this country. For instance, the relative weight given by the government to the exchange rate fluctuations or the one given to the inflation rate fluctuations against the output fluctuations depends on the monetary and fiscal policies of the government at any moment. Therefore, finding a numerical solution to this problem requires studies which can find the parameters of this model as regards the economic conditions of Iran.

Based on the recursive equilibrium law of motion of the exchange rate (19) and $E\left(\varepsilon_{t+1}\right)=0$, the optimal volume of foreign exchange intervention in the market is merely a function of the exchange rate targeted by the government for the next period (future time), the exchange rate at present, and a constant as intercept:

$$
\zeta_{t}=\frac{-a_{2}}{a_{1}+a_{2} \gamma} x_{t+1}-\frac{a_{2} a_{3}}{a_{1}+a_{2} \gamma} x_{t}-\frac{c_{1}}{a_{1}+a_{2} \gamma}
$$

Ceteris paribus, intervention of the monetary authority in the market is carrried out based on the expected exchange rate $\left(x_{t+1}\right)$. Due to the monopoly power of the government in the exchange market, the volume of foreign exchange intervention depends on the level the government attempts to maintain the foreign exchange rate in the next period. This is attributable to the fact that foreign exchange intervention affects the exchange rate both at present and in the future. In other words, elasticity of the foreign exchange intervention with respect to the exchange rate of the next period and elasticity of the foreign exchange intervention with respect to the exchange rate of the present period are:

$$
\begin{aligned}
& \frac{\partial \zeta_{t}}{\partial x_{t+1}}=-\frac{a_{2}}{a_{1}+a_{2} \gamma} \\
& \frac{\partial \zeta_{t}}{\partial x_{t}}=-\frac{a_{2} a_{3}}{a_{1}+a_{2} \gamma}
\end{aligned}
$$

Comparing these two relations indicates that the effect of the present exchange rate on the volume of intervention is more than the effect of the exchange rate in the future period. In fact, the effect of the present exchange rate on the volume of intervention, resulting from the exogenous economic pressures (pressure of the financing of the government budget), as well as exogenous economic fluctuations due to other factors, is higher than the effect of the exchange rate in the next period. Obviously, the exchange rate in Iran is not solely determined on the basis of the market mechanisms; therefore, the determinant of the volume of intervention by the monetary authority at the present time is the level that the government attempts to keep the exchange rate at present and in the future. This is due to the fact that in the Iranian economy, the government is traditionally the main supplier of foreign exchange to the market. The present and future levels of the exchange rate depend on the government budget expenditures and the government foreign exchange expenditures. This in turn depends on the government size and its reliance on foreign exchange revenues received from the sale of the national wealth. The elasticities are in fact indicative of the fact that the exchange rate in Iran is a short-term policy instrument at the disposal of the competent authorities whereas it should be a key rate emanating from the economy and the performance of the forces involved in it.

According to the Uhlig program and equations (15) and (18), the inflation rate is: 


$$
\pi_{t}=\pi_{t-1}+\left(a_{4}+a_{8} a_{6}\right) \pi_{t-2}-a_{5} a_{3} X_{t-2}-a_{5}\left(\gamma+\frac{a_{1}}{a_{2}}\right) \zeta_{t-2}-\frac{a_{5}}{a_{2}} c_{1}-a_{5} \varepsilon_{t-1}+a_{6} y_{t-2}+a_{6} a_{7} y_{t-3}+a_{6} V_{t-2}+u_{t-1}
$$

Inflation at the present time $\left(\pi_{t}\right)$ is a function of the inflation of the previous period $\left(\pi_{t-1}\right)$, inflation of two periods before $\left(\pi_{t-2}\right)$, the exchange rate of two previous periods $\left(x_{t-2}\right)$, volume of foreign exchange intervention in two previous periods $\left(\zeta_{t-2}\right)$, output in two previous periods $\left(y_{t-2}\right)$, output in three previous periods $\left(y_{t-3}\right)$, exchange rate shock of the previous period $\left(\varepsilon_{t-1}\right)$, inflation shock of the previous period $\left(u_{t-1}\right)$, and the output shock of two previous periods $\left(v_{t-2}\right)$. It is of special note that the exchange rate of the previous period, output of the previous period, and the volume of the foreign exchange intervention of the previous period show its own effect through the increase in the inflation rate. Moreover, the exchange rate of the previous period exists in the foreign exchange intervention variable of two previous periods. Output rate of the previous period shows itself in inflation variable of the previous period. Therefore, they are not directly included in the above equation.

The exchange rate is a key macroeconomic indicator which has a significant effect on the inflation. In the economic literature, the exchange rate affects the inflation through three channels. First is the direct channel by which the exchange rate influences the prices of imported goods such as raw materials and intermediate goods used for domestic production, with a short time lag. Meanwhile, it indirectly affects the domestic prices of local goods competing with their imported counterparts through arbitrage. When the share of import in GDP is high, the reliance of the economy on imports is high as well; therefore, this channel will be stronger. In other words, due to the high share of import in GDP, the level of prices will be further affected by the exchange rate.

The second channel is indirect where exchange rate changes, ceteris paribus, affect the real exchange rate. This will in turn affect the economy through the aggregate demand and the output gap. With depreciation of the domestic currency, domestically produced goods and exports will be supplied to the foreigners at lower prices, leading to an expansion in the exports and aggregate demand compared with the potential output over the short run. Depreciation of domestic currency causes price level to rise. Since nominal wages are rigid in short term, real wages will decline and the output will surge. Besides these channels, there is an expectation channel based on which, continuous exchange rate fluctuations lead to the adjustment of public expectations regarding prices, as well as a growth in exchange rate pass-through effect on the inflation. There is a higher correlation between inflation and the rise in the nominal exchange rate in uncertain monetary conditions by which nominal shocks lead to high inflation and currency depreciation.

Therefore, based on the Uhlig program and equations (15) through (18), output variable is calculated as follows:

$$
y_{t}=y_{t-1}+\left(a_{7}+a_{8} a_{6}\right) y_{t-2}+a_{8} \pi_{t-2}+a_{8} a_{4} \pi_{t-3}+a_{8} a_{5} x_{t-2}+a_{8} u_{t-2}+v_{t-1}
$$

Output level at present time $\left(y_{t}\right)$ depends on the output of the previous period $\left(y_{t-1}\right)$, output of two previous periods $\left(y_{t-2}\right)$, inflation of two previous periods $\left(\pi_{t-2}\right)$, inflation of three previous periods $\left(\pi_{t-3}\right)$, exchange rate of two previous periods $\left(x_{t-2}\right)$, inflation shock of two previous periods $\left(u_{t-2}\right)$, and output shock of the previous period $\left(v_{t-1}\right)$. Exchange rate and inflation shock of the previous period affect output through inflation. In other words, output at present time depends on the exchange rate and inflation in addition to output in previous periods.

Rise in the exchange rate and inflation will each lead to an increase in marginal cost of production, causing uncertainty in production. Therefore, in order to maintain output at full employment level, it is deemed essential that parameters such as exchange rate and inflation should enjoy admissible stability and output institutional weaknesses should be taken into consideration.

Based on the designed model, inflation, in addition to its lags, is a function of exchange rate and the level of domestic output. Therefore, inflation targeting policy could help trigger the output and stabilize the exchange rate. Precluding the uncontrollable growth of liquidity is a prerequisite to the curbing of inflation. In the Iranian economy, government budget policies are a significant factor behind the rise in liquidity. Since the government general budget is strongly dependent on oil revenues, the Central Bank will inevitably have to finance the budget (in Rials) through the exchange of dollars received from the sale of oil. Due to the lack of capacities in the economy to absorb the foreign exchange received from the sale of oil, the Central Bank eventually enters the market to purchase the excess demand of foreign currency. If the composition of government foreign exchange 
revenues and expenditures is revised and the reliance of the general budget on the revenues received from the sale of the national wealth decreases, foreign exchange intervention based on the exchange rate financing the budget will not occur, thereby reducing the pressure on the exchange rate.

\section{Conclusion}

The present article pioneers the designing of a theoretical model for the determination of the optimal foreign exchange intervention in the Iranian market. The model used in this article is a nonlinear dynamic programming model with stochastic continuous functions to solve which the Uhlig program has been used. The result of the model's solution indicates that determining the best volume of intervention depends on the economic objectives of policymakers, the exchange rate of the present time, and the future exchange rate expected by the monetary authorities. Due to the monopolistic condition of the government in the foreign exchange market, the volume of the foreign exchange intervention in the market depends on the level the government is trying to keep the exchange rate at the present time as well as the next period. This is attributable to the fact that foreign exchange intervention affects the exchange rate of both the present time and the future.

Results of the model depict that the exchange rate elasticity at the present time with respect to the exchange rate of the previous period is a function of exogenous economic pressures (such as financing the government general budget), and the exogenous fluctuations of the exchange rate due to other economic variables namely, the oil price fluctuations in international markets. By and large, vulnerability of the exchange rates of two consecutive periods, ceteris paribus, depends on the upward and downward pressures of the exchange rate and the exogenous fluctuations of the exchange rate.

Elasticity of the exchange rate with respect to the foreign exchange intervention of the previous period depends on a host of parameters including the coefficient of the effect of foreign exchange intervention on the exchange rate, the relative weight given by the Central Bank to exchange rate deviations from the exchange rate target, Central Bank exchange rate target, different effects of the exchange rate deviations above and below the exchange rate target, cost factor of the foreign exchange intervention, discount rate of Central Bank costs, and the volume of the exchange rate in the steady state. If Central Bank costs (costs of fluctuations of exchange rate, inflation rate, output, and then foreign exchange intervention) are discounted with a higher rate, exchange rate elasticity with respect to foreign exchange intervention of the previous period will be lower. If effects of foreign exchange intervention are high, the elasticity is high as well. If the cost factor of exchange rate intervention is higher, the elasticity is higher too.

Findings indicate that the effect of the exchange rate of the present period on the volume of intervention is more than the effect of the exchange rate of the next period. In other words, the effect of the present exchange rate on the volume of intervention depends on the exogenous economic pressures (pressures of financing of government general budget) and exogenous economic fluctuations due to other factors are higher than the effect of the exchange rate of the next period. The determinant of the volume of foreign exchange intervention by the monetary authority at the present period is the government budget which in turn depends on government foreign exchange expenditures in the economy.

Findings of the model are also indicative of the fact that current inflation rate, in addition to previous inflation rates, depends on the exchange rate, volume of foreign exchange intervention, output, and shocks in the economy. Output at the present period, in addition to the output of the previous periods, depends on the exchange rate, inflation rate, and inflationary and output shocks, at the same time. Therefore, in order to raise the amount of output, exchange rate and inflation are the two key variables which need to be taken into account on top of output institutional weaknesses. Rise in the exchange rate and inflation can each be a contributing factor to the increase in the costs of production and rise of uncertainty. As a result, to keep output at a certain level, economic fundamentals, particularly exchange rate and inflation, need to be stable.

As mentioned earlier, to find a numerical solution to this problem, the exact value of parameters must be known. This can either be achieved by extraction from the reference models or calculated specifically for the Iranian economy. The former is not really plausible in the economy of Iran. This being the case, it is advisable that studies be conducted with the aim of calculating the parameters of this model, considering the specific economic condition of Iran. This is the undertaking the future studies can take care of the problem.

\section{References}

Cadenillas, A., \& Zapatero, F. (1999). Optimal Central Bank Intervention in the Foreign Exchange Market. Journal of Economic Theory, 87, 218-242. http://dx.doi.org/10.1006/jeth.1999.2523

Cadenillas, A., \& Zapatero, F. (2000). Classical and Impulse Stochastic Control of the Exchange Rate Using 
Interest Rates and Reserves. Mathematical Finance, 10(2). http://dx.doi.org/10.1111/1467-9965.00086

Campbell, J. Y., \& Cochrane, J. H. (1998). By Force of Habit: A Consumption-Based Explanation of Aggregate Stock Market Behavior. Center for Research in Security Prices (CRSP) Working Paper, 412, Harvard University.

Chadha, J. S., \& Nolan, C. (2004). Output, Inflation and the New Keynesian Philips Curve. International Review of Applied Economics, 18(3), 271-287. http://dx.doi.org/10.1080/0269217042000227060

Deravi, K., Gregorowicz, P., \& Hegji, C. E. (1995). Exchange Rates and the Inflation Rate. Quarterly Journal of Business and Economics, 34(1).

Evans, L. C. (2010). An Introduction to Mathematical Optimal Control Theory. Department of Mathematics, University of California, Berkeley, version 0.2.

Gong, G., \& Smeller, W. (2004). Stochastic Dynamic Macroeconomics: Theory, Numeric and Empirical Evidence. Center for Empirical Macroeconomics, Bielefeld, and New School University, New York.

Hafer, R. W. (1989). Does Dollar Depreciation Cause Inflation. Federal Reserve Bank of St. Louis Review, 71, $16-28$

Kahn, G. A. (1987). Dollar Depreciation and Inflation. Federal Reserve Bank of Kansas City. Economic Review, November, 32-49.

Karatzas, I., \& Shreve, S. E. (1991). Brownian Motion and Stochastic Calculus (2nd ed.). New York: Springer Verlag.

Ljungqvist, L., \& Sargent, T. J. (2000). Recursive Macroeconomic Theory (2nd ed.). MIT.

Mishkin, F. (2008). Exchange Rate Pass-Through and Monetary Policy. Board of Governors of the Federal Reserve System, Norges Bank Conference on Monetary Policy, Oslo, Norway.

Mundaca, G., \& Oksendal, B. (1998). Optimal Stochastic Intervention Control with Application to the Exchange Rate. Journal of Mathematical Economics, 29, 225-243. http://dx.doi.org/10.1016/S0304-4068(97)00013-X

Onishi, M., \& Tsujimura, M. (2006). An Impulse Control of a Geometric Brownian Motion with Quadratic Costs. European Journal of Operational Research, 168, 311-321. http://dx.doi.org/10.1016/j.ejor.2004.07.006

Taylor, L. (1991). Income Distribution, Inflation and Growth. Lectures on Structuralist Macroeconomics Theory, 3-50.

Tsay, R. S. (2005). Analysis of Financial Time Series. Wiley Series in Probability and Statistics, 250-270.

Uhlig, H. (1999). A Toolkit for Analyzing Nonlinear Dynamic Stochastic Models Easily. Discussion Paper, 97, Tilburg University, Center for Economic Research.

\section{Note}

Note 1. In mathematics, a function $\mathrm{E}$ defined on some set $\mathrm{X}$ with real or complex values (Metric Space) is called bounded, if the set of its values is bounded. In other words, there exists a real number $\mathrm{M}<\infty$ and the point $\mathrm{q}$ in set $\mathrm{X}$ such that $d(p, q)\langle M$ for all $\mathrm{p}$ in $\mathrm{E}$.

\section{Copyrights}

Copyright for this article is retained by the author(s), with first publication rights granted to the journal.

This is an open-access article distributed under the terms and conditions of the Creative Commons Attribution license (http://creativecommons.org/licenses/by/3.0/). 